\title{
Oral administration of Enterococcus faecalis FK-23 suppresses Th17 cell development and attenuates allergic airway responses in mice
}

\author{
BEI ZHANG ${ }^{1}$, JUN AN ${ }^{1}$, TAKASHI SHIMADA ${ }^{2}$, SHUANG LIU $^{1}$ and KAZUTAKA MAEYAMA ${ }^{1}$ \\ ${ }^{1}$ Department of Pharmacology, Informational Biomedicine, Ehime University Graduate School of Medicine, Shitsugawa, \\ Toon-shi, Ehime 791-0295; ${ }^{2}$ Central Research Laboratories, Nichinichi Pharmaceutical Co., Ltd., Mie 518-1417, Japan
}

Received February 3, 2012; Accepted April 13, 2012

DOI: $10.3892 /$ ijmm.2012.1010

\begin{abstract}
Evidence is increasing that oral administration of probiotics can attenuate asthmatic responses both in murine models and clinical trials. T-helper 17 (Th17) cells, a subset of $\mathrm{CD}^{+} \mathrm{T}$ cells have been implicated as having an important role in the development of several allergic disorders, but the relationship between oral administration of probiotics and Th17 development has not been well studied. BALB/c mice were given lysed Enterococcus faecalis FK-23 (LFK) orally for 28 days. After sensitization by subcutaneous injection of ovalbumin (OVA) on Days 14 and 21 and 1\% OVA inhalation on Days 25, 26 and 27, they were challenged with a 5\% OVA aerosol on Day 28. Twenty-four hours later, airway resistance and accumulation of inflammatory cells in bronchoalveolar lavage fluid (BALF) and lung tissues were determined. Interleukin (IL)-17-expressing $\mathrm{CD}^{+}$lymphocytes isolated from lung, spleen and lamina propria of the intestine were detected by flow cytometry. The expression of IL- 6 and TGF- $\beta$ mRNA was assessed by real-time PCR. Increases in airway hyperresponsiveness, and numbers of total leukocytes and mast cells in BALF induced by OVA challenge were significantly suppressed by oral administration of LFK. The increased percentage of $\mathrm{IL}-17$-expressing $\mathrm{CD}^{+}$cells from lung, spleen and intestine in OVA-challenged mice was reduced following LFK treatment. We conclude that the oral administration of LFK suppresses the asthmatic response and that this is associated with attenuation of Th17 cell development.
\end{abstract}

\section{Introduction}

Allergic asthma is conventionally characterized by an increase in serum immunoglobulin $\mathrm{E}$ and the accumulation and acti-

Correspondence to: Dr Shuang Liu, Department of Pharmacology, Informational Biomedicine, Ehime University Graduate School of Medicine, Shitsugawa, Toon-shi, Ehime 791-0295, Japan

E-mail: liussmzk@m.ehime-u.ac.jp

Key words: allergic asthma, T-helper 17 cells, Enterococcus faecalis vation of Th2 cells, eosinophils and mast cells. Recently, T-helper 17 (Th17) cells, a CD4 ${ }^{+}$helper $\mathrm{T}$ cell subset that produces interleukin-17A (IL-17A) and IL-17F, have been discovered to play important roles in allergic responses such as delayed-type hypersensitivity, contact hypersensitivity, and allergic airway inflammation (1). IL-17 promotes inflammation by inducing different proinflammatory cytokines and chemokines, recruiting neutrophils, enhancing antibody production, and activating $\mathrm{T}$ cells. Overexpression of IL-17A and IL-17F in the lungs leads to increased proinflammatory cytokine and chemokine expression, causing inflammation associated with neutrophil infiltration (2-5). IL-17 mRNA and/ or protein was reported to be increased in the lungs, sputum, bronchoalveolar lavage fluids and sera from asthmatics, and the levels of IL-17 were correlated with the degree of severity of airway hypersensitivity (6).

Accumulating evidence suggests that certain probiotics may contribute to the development of immune function in the gastrointestinal tract. In particular, there is growing interest in the therapeutic potential of these organisms in allergic disorders. Clinical trials have indicated that oral administration of certain organisms can modulate immune responses in the airway (7-9). Live Lactobacillus reuteri significantly attenuated the development of experimental allergic asthma in one study (9). The development of mucosal and systemic tolerance seems to rely on immunosuppressive mechanisms orchestrated by regulatory $\mathrm{T}$-cell classes that attenuate both Th1 and Th2 responses (10). However, the involvement of Th17 cells and anti-allergic action of certain bacteria remains obscure.

To seek evidence for an association between the suppression of allergic airway responses induced by certain microorganisms and the presence of Th17 cells, we investigated the expression of Th17 cells in a murine allergic asthma model. A product of lysozyme and heat-treated Enterococcus faecalis FK-23, LFK was orally administered to asthmatic mice with a view to decreasing airway inflammation. We had previously shown that LFK inhibited active cutaneous anaphylaxis and allergen-induced peritoneal accumulation of eosinophils in murine models $(11,12)$. The potential role of Th17 cells in LFK-mediated attenuation of allergic airway inflammation is described in the present study. 


\section{Materials and methods}

Preparation of LFK. LFK was prepared as previously described $(11,12)$. In brief, Enterococcus faecalis FK-23 was cultured for $24 \mathrm{~h}$ at $37^{\circ} \mathrm{C}$, in a broth medium containing $2 \%$ glucose, $2 \%$ yeast extract and $4 \% \mathrm{KH}_{2} \mathrm{PO}_{4}$. The cells were harvested by centrifugation, washed three times with distilled water and then treated with lysozyme $(1 \mathrm{mg} / \mathrm{ml})$ at $37^{\circ} \mathrm{C}$ for $2 \mathrm{~h}$, heated to $105^{\circ} \mathrm{C}$ for $10 \mathrm{~min}$, then lyophilized.

Other compounds. Methacholine chloride and ISOGEN were purchased from Wako Pure Chemical Industries (Osaka, Japan). Ovalbumin (OVA), Percoll, phorbol myristate acetate (PMA), ionmycin and DNase I were obtained from Sigma Chemical Co. (St. Louis, MO, USA). Collagenase D and dispase were from Roche Diagnostics GmbH (Mannheim, Germany).

Animal. Male BALB/c mice (20-25 g) (Japan SLC, Hamamatsu, Japan) were used. They were housed at a constant temperature of $22 \pm 2^{\circ} \mathrm{C}$ with a humidity of $55 \pm 10 \%$ on an automatically controlled 12:12 h light-dark cycle, and given food and water ad libitum. Animal care and research protocols were in accordance with the principles and guidelines adopted by the Animal Care Committee of Ehime University and approved by the University Committee for Animal Research.

Administration of LFK and sensitization. Mice were given LFK $(60 \mathrm{mg})$ in $0.5 \mathrm{ml}$ saline every day for 28 days. Mice given only saline were used as controls (Fig. 1). Mice were sensitized by subcutaneous injection of $20 \mu \mathrm{g}$ OVA adsorbed to $500 \mu \mathrm{g}$ aluminum hydroxide suspension in saline on Day 14. A booster injection of OVA was given on the Day 21. Sensitized mice were exposed to $1 \%$ OVA for $30 \mathrm{~min}$ by inhalation on Days 25, 26 and 27, followed by inhalation of 5\% OVA on Day 28. Mice challenged with saline were used as controls (Fig. 1).

Measurement of airway hypersensitivity. Twenty-four hours after the final OVA challenge, bronchial reactivity to aerosolized methacholine was measured using a whole-body plethysmographic chamber (Buxco Electronics, Sharon, CT, USA) to determine changes in enhanced respiratory pause $(\mathrm{PenH})$. After a 10-min stabilization period, increasing concentrations of methacholine $(2-32 \mathrm{mg} / \mathrm{ml})$ or saline were aerosolized for $1 \mathrm{~min}$ each, and mean PenH values were obtained over 5-min periods. PenH (= pause x PEP/PIP) describes airway resistance, using the peak expiratory pressure (PEP) and the peak inspiratory pressure (PIP). The pause was defined as (Tc-Tr)/Tc, where $\mathrm{Tc}$ is the time of expiration and $\mathrm{Tr}$ is the relaxation time. The $\mathrm{Tr}$ was the time of pressure decay to $30 \%$ of the total expiratory pressure signal. Constriction of the airway is shown as the increased $\mathrm{PenH}$ value.

Leukocyte accumulation in bronchoalveolar fluid (BALF). Twenty-four hours after challenge with OVA or saline, BALF was collected via tracheal cannulation using $250 \mu 1$ phosphatebuffered saline solution (PBS, pH 7.20). Collections were repeated 3 times on each mouse. Routinely, $>90 \%$ of the lavage fluid was recovered from the lungs. Cells were removed from BALF by centrifugation at $200 \mathrm{x}$ g for $15 \mathrm{~min}$ and BALF cell pellets were pooled and resuspended in PBS for total and differential cell counts.

The morphology of BALF cell preparations was analyzed using light microscopy. Air-dried preparations were fixed and stained with hematoxylin and eosin (H\&E) to determine the total cell number. The other preparations were stained with Alcian blue and nuclear fast to identify mast cells. Results are expressed as the number of cells per lung.

Histological analysis. Lung sections were stained with H\&E after fixation with $4 \%$ paraformaldehyde in $0.1 \mathrm{M}$ phosphate buffer (pH 7.20) for $12 \mathrm{~h}$ at $4^{\circ} \mathrm{C}$. All sample slides were examined using a Nikon $\mathrm{C} 1$ microscope (Nikon, Japan) and compared at the same magnification.

Analysis of Th17 cells in lungs, spleens and lamina propria of the intestine. Twenty-four hours after the final OVA challenge, tissues were removed and cells were isolated. Splenocytes were isolated from spleens using a standard dissection technique and resuspended in RPMI-1640 for staining (13). For isolation of lung cells, briefly, lungs were cut into small pieces and digested in $10 \mathrm{ml}$ of medium containing $300 \mathrm{U} / \mathrm{ml}$ collagenase D and $1.5 \mathrm{mg} / \mathrm{ml}$ DNase I at $37^{\circ} \mathrm{C}$ for $1 \mathrm{~h}$. The digested lung tissue was filtered through a $70 \mu \mathrm{m}$ cell strainer, after red blood cells had been lysed (14). For isolation of intestinal lamina propria lymphocytes, the intestines were opened longitudinally and shaken in Hanks' balanced salt solution containing 5 mM EDTA$\mathrm{Na}_{2}$ for $20 \mathrm{~min}$ at $37^{\circ} \mathrm{C}$. Small pieces of intestine were incubated with RPMI-1640 containing $4 \%$ fetal bovine serum, $1 \mathrm{mg} / \mathrm{ml}$ collagenase D, $1 \mathrm{mg} / \mathrm{ml}$ dispase and $40 \mu \mathrm{g} / \mathrm{ml}$ DNase I for $1 \mathrm{~h}$ at $37^{\circ} \mathrm{C}$ in a shaking water bath. Then the digest was resuspended in $40 \%$ Percoll and overlayed on $80 \%$ Percoll. After centrifugation, the lamina propria lymphocytes from the interface of the Percoll gradients were collected immediately for intracellular cytokine staining (15). Dispersed cell suspensions from lungs, spleens and lamina propria were resuspended at $1 \times 10^{6}$ cells $/ \mathrm{ml}$ and incubated with $50 \mathrm{ng} / \mathrm{ml}$ PMA, $500 \mathrm{ng} / \mathrm{ml}$ ionomycin in RPMI-1640 at $37^{\circ} \mathrm{C}$ for $6 \mathrm{~h}$. After extracellular staining with $\mathrm{PE}$ anti-mouse $\mathrm{CD} 4$, the cells were permeabilized with Fix/ Perm solution for $20 \mathrm{~min}$ at $4^{\circ} \mathrm{C}$. They were then stained with Alexa Fluor 488 anti-mouse IL-17A. Data were acquired on a BD FACSAria (Becton-Dickinson, Oakville, ON, Canada) and analyzed using FlowJo (Tree Star Inc., Ashland, OR, USA)

Quantitative real-time PCR. Total-RNA was extracted with ISOGEN from lungs, spleens and intestines of mice $24 \mathrm{~h}$ after the final challenge. The expression of TGF- $\beta$, IL- 6 and $\beta$-actin mRNA was assessed according to the manufacturer's instruction using the One Step SYBR PrimeScript Plus RT-PCR kit (Takara Bio, Inc., Shiga, Japan). The fluorescence emission of the probe was monitored and analyzed using an Applied Biosystems 7500 Fast Real-Time PCR system (Applied Biosystems). Specific oligonucleotide primers were designed according to published sequences as shown in Table I. The expression levels of IL- 6 and TGF- $\beta$ were corrected by reference to $\beta$-actin, and the relative amount of each mRNA in each sample was calculated by the comparative $\Delta \mathrm{Ct}$ method.

Statistical analyses. All experiments were designed as completely randomized multifactorials with 3-15 mice/group. 
Table I. Sequences of PCR primers.

\begin{tabular}{lll}
\hline Target & Forward sequence $\left(5^{\prime} \rightarrow 3^{\prime}\right)$ & Reverse sequence $\left(5^{\prime} \rightarrow 3^{\prime}\right)$ \\
\hline TGF- $\beta$ & GACTCTCCACCTGCAAGACCA & GGGACTGGCCGAGCCTTAGTT \\
IL-6 & TTCCATCCAGTTGCCTTCTTG & TTGGGAGTGGTATCCTCTGTGA \\
$\beta$-actin & AGAGGGAAATCGTGCGTGAC & CAATAGTGATGACCTGGCCGT \\
\hline
\end{tabular}

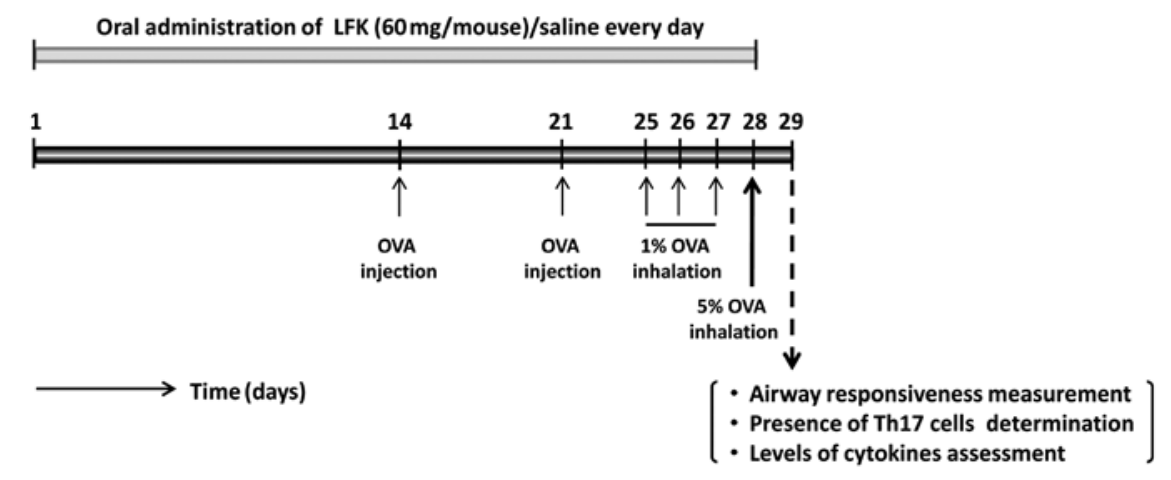

Figure 1. Study design. Male BALB/c mice were administered LFK or saline orally for 28 days. On Day 14, mice used for establishment of the asthmatic model were sensitized by subcutaneous injection of OVA mixed with aluminum hydroxide suspension in physiological saline. A booster injection of OVA was given after 7 days. Sensitized mice were exposed to 1\% OVA by inhalation on Days 25, 26 and 27, followed by 5\% OVA inhalation on Day 28 . The measurement of airway responsiveness and bronchoalveolar lavage fluid sample collection and tissue harvesting was performed 1 day after the final challenge.

Results are expressed as the mean \pm SEM. The significance of the differences among all groups were analyzed using repeated measures analysis of variances (ANOVA) followed by the Scheffe's F-test. Significant differences between treatments were assessed using Student's t-test. P-values $<0.05$ were taken to indicate significant differences.

\section{Results}

Suppression of allergic airway inflammation by oral administration of $L F K$. We determined the effect of LFK on airway hyperresponsiveness, one of the most important characteristics of the allergic airway response. Suppression of airway hyperresponsiveness, reduced accumulation of leukocytes in BALF and less lung inflammation were seen following oral administration of LFK. Thus, the final OVA challenge to OVA-sensitized mice resulted in an enhanced response to methacholine as determined by an enhanced pause index, but this was significantly attenuated by oral administration of LFK for 28 days (Fig. 2A). Administration of LFK alone did not have any effects on airway resistance in non-sensitized mice.

Oral treatment with LFK also attenuated inflammatory cell influx into the airway. The total number of cells in BALF increased by 1.74 -fold $(\mathrm{P}<0.05) 24 \mathrm{~h}$ after the final antigen challenge in OVA-sensitized (saline-treated/OVA-challenged) mice compared with the saline-treated/saline-challenged controls (Fig. 2B). LFK-treated/OVA-challenged mice showed a significant reduction in total cells recovered in BALF to $71.8 \%(\mathrm{P}<0.05)$ compared to saline-treated/OVA-challenged mice.

The OVA challenge also caused a marked increase in the proportion of mast cells present (Fig. 2C), one of the most important functional cell populations in the allergic airway response. In the LFK-treated/OVA-challenged group, the number of mast cells was significantly decreased to $50.9 \%$ of the saline-treated/OVA-challenged mice. This result is in line with the marked decrease in total numbers following administration of LFK.

The anti-allergic effect of LFK on airway inflammation was also observed in histological analysis. The administration of LFK to OVA-challenged mice resulted in decreased perivascular and peribronchiolar infiltration by inflammatory cells (Fig. 2D). Thus, suppression of airway inflammation as a result of oral administration of LFK was clearly demonstrated in this model.

Effect of LFK on the presence of Th17 cells in lung. To investigate the effect of oral administration of LFK on the development of Th17 cells, we assessed IL-17 expression in isolated lymphocytes from the lung after oral treatment with LFK for 28 days. In the LFK-treated/saline-challenged mice, the percentage of IL-17-expressing $\mathrm{CD}^{+}$cells in the lung was reduced to $43.5 \%(\mathrm{P}<0.05)$ compared to saline-treated/salinechallenged mice. OVA sensitization and challenge dramatically increased IL-17-expressing $\mathrm{CD}^{+}$cells in the lung, showing a 2.4-fold increase compared with the saline-sensitized and challenged mice. However, this robust development of Th17 cells was attenuated by LFK administration, which resulted in a significant decrease of the percentage of IL-17-expressing $\mathrm{CD}^{+}$cells in LFK-treated/OVA-challenged mice, to $23.8 \%$ $(\mathrm{P}<0.05)$ compared to saline-treated/OVA-challenged mice (Fig. 3A and B).

Oral treatment with LFK also markedly reduced TGF- $\beta$ expression to $8.7 \%(\mathrm{P}<0.05)$ and IL-6 to $1.3 \%(\mathrm{P}<0.05)$ of that seen in saline-treated/OVA-challenged mice (Fig. 3C and D). Thus, LFK had marked effects on several related cytokines 

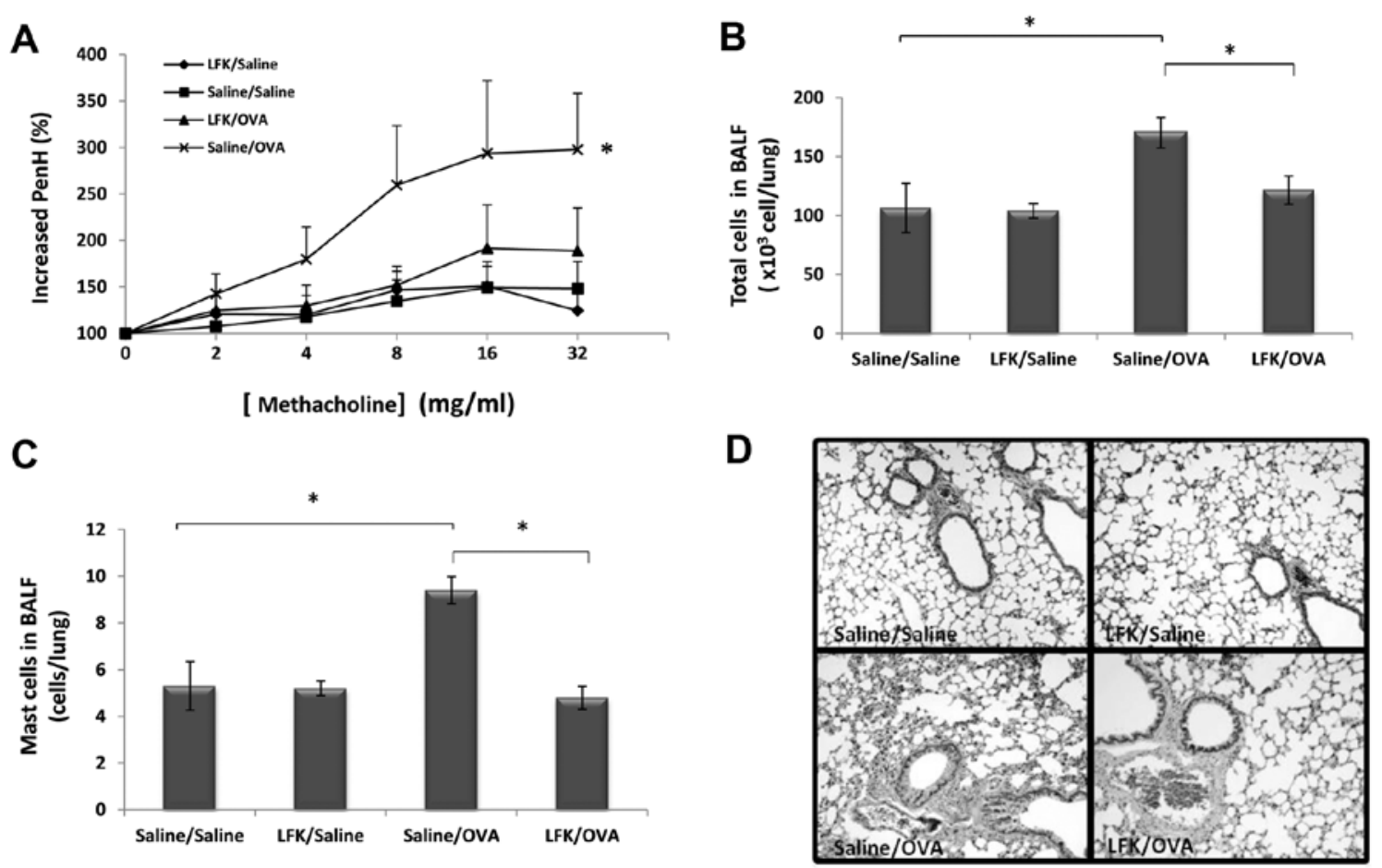

Figure 2. Suppression of allergic airway inflammation by administration of LFK. (A) Changes in airway hypersensitivity were quantified using the enhanced pause index, which was measured using a whole-body plethysmograph. For each experiment, increasing concentrations of methacholine (2-32 mg/ml) or saline were aerosolized for $1 \mathrm{~min}$ each, and mean PenH values were obtained over 5 -min periods. The results are expressed as the mean $\pm \mathrm{SEM}$. $\mathrm{P}<0.05$, ANOVA followed by Scheffe's test for differences in saline-treated/OVA-challenged mice (x-marks), LFK-treated/OVA-challenged mice (triangles), LFK-treated/salinechallenged mice (diamonds) and saline-treated/saline-challenged mice (squares). (B) Total number of cells in bronchoalveolar lavage fluid (BALF) taken from mice $24 \mathrm{~h}$ after challenge by inhalation of $5 \%$ OVA. The BALF cells were analyzed by H\&E staining. Mice challenged with saline were used as controls. ${ }^{*} \mathrm{P}<0.05$, Student's t-test, compared with each group. (C) The number of mast cells in BALF. Mast cells were detected by Alcian blue/nuclear fast staining. * $\mathrm{P}<0.05$, Student's t-test, compared with each group. (D) Histological analysis of the lung. The lung sections were stained by H\&E. All sample slides were examined using a Nikon C1 microscope (Nikon, Japan) and compared at the same magnification ( $\mathrm{n}=5-15$ mice/group).

A
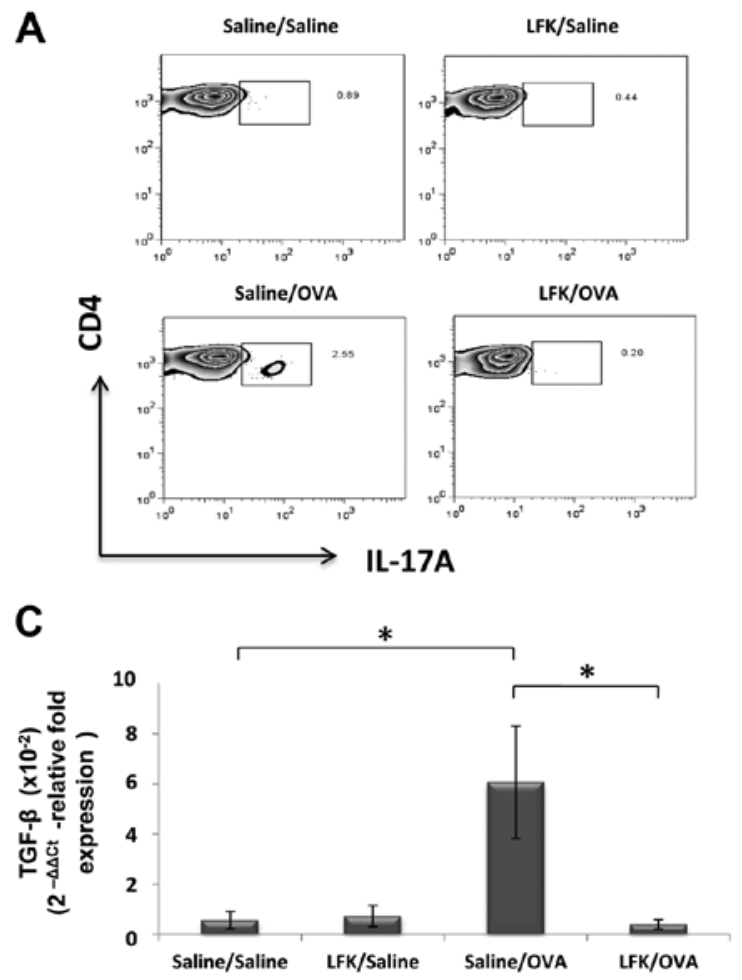

B
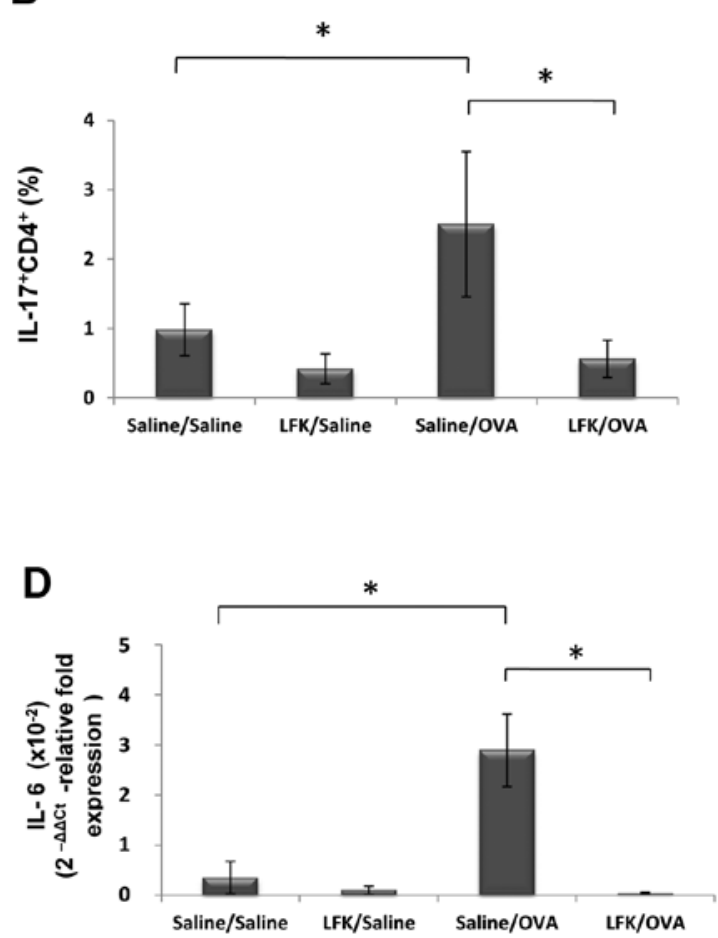

Figure 3. LFK suppresses the development of Th17 cells and the expression of related cytokines in the lung. Total lung cells were isolated 1 day after final OVA provocation. (A) Representative plots and (B) combined data of CD4 and IL-17 expression in total lung cells are shown. Data are from one of at least 5 separate experiments with similar results. (C) IL-6 and (D) TGF- $\beta$ mRNA expression in the lung was detected by real-time PCR, as described in Materials and methods. ${ }^{\mathrm{P}}<0.05$, Student's t-test compared with each group ( $\mathrm{n}=5-10$ mice/group). 
A

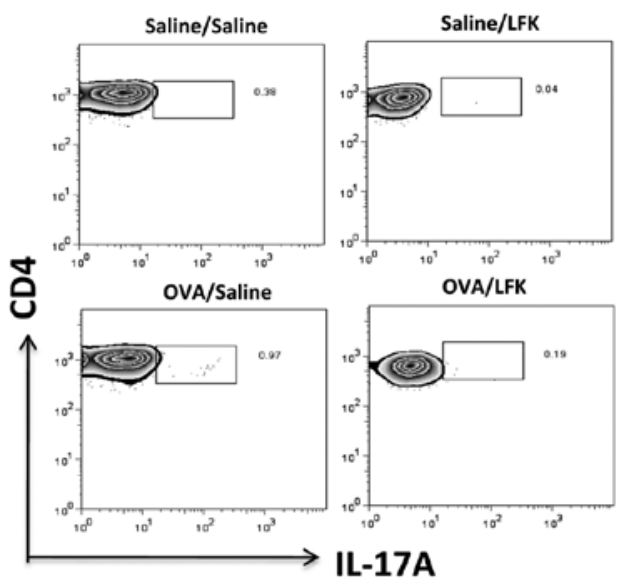

C

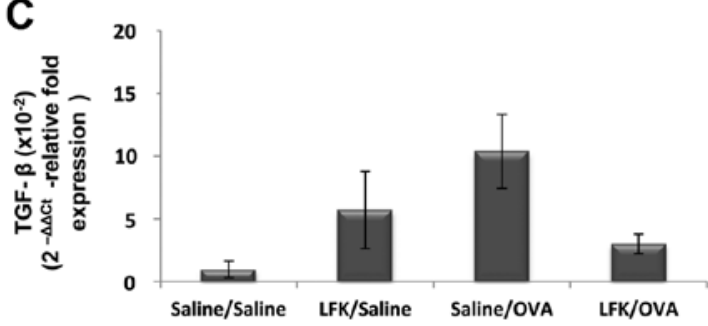

B
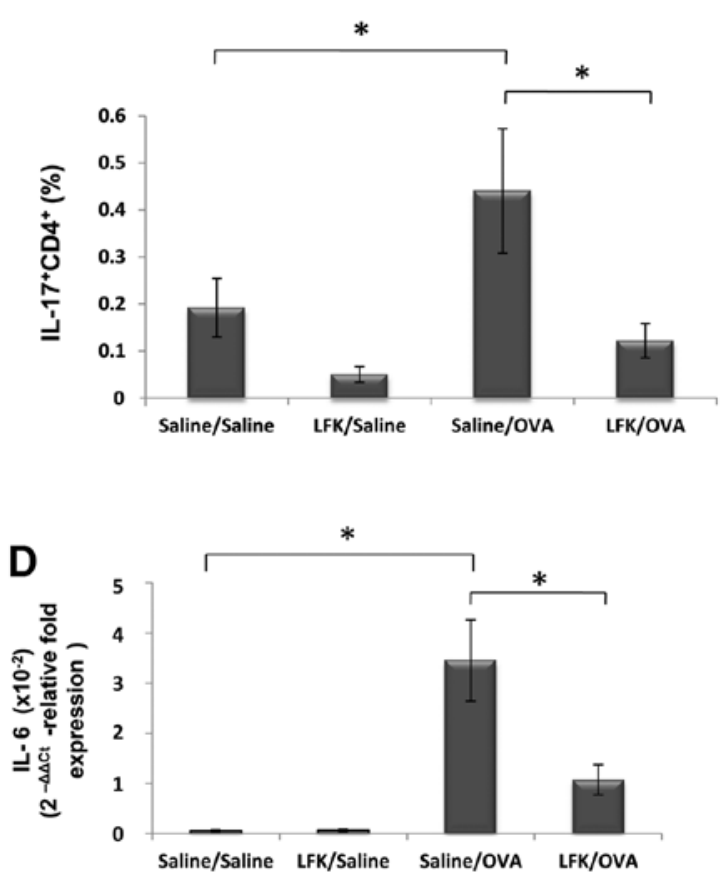

Figure 4. Th17 cells and related cytokines in splenocytes. Splenocytes were isolated from spleens 1 day after final OVA provocation. (A) Representative plots and (B) combined data of CD4 and IL-17 expression in splenocytes are shown. Data are from one of at least 5 separate experiments with similar results. (C) IL-6 and (D) TGF- $\beta$ mRNA expression in spleen was quantified by real-time PCR as described in Materials and methods. "P<0.05, Student's t-test compared with each group. ( $n=5-10 \mathrm{mice} /$ group).

and reduced the development of Th17 cells in allergic airway inflammation.

Effect of LFK on the presence of Th17 cells in splenocytes. The changes in the percentage of IL-17-expressing CD4 ${ }^{+}$cells in splenocytes showed a similar tendency as in isolated lung cells. Oral administration of LFK reduced the percentage of IL-17-expressing CD4 ${ }^{+}$cells to $26.2 \%(\mathrm{P}<0.05)$ compared with saline-treated/OVA-challenged mice (Fig. 4A and B). Again, the expression of IL-6 was also decreased to $33.3 \%(\mathrm{P}<0.05)$, and the reduction of TGF- $\beta$ did not achieve significance.

Effect of LFK on the presence of Th17 cells in the intestine. To test whether LFK suppresses Th17 cells in a crucial location, IL-17-expression of CD4 ${ }^{+} \mathrm{T}$ cells in the intestinal lamina propria was investigated. IL-17-expressing $\mathrm{CD}^{+}$cells in the intestine was increased 1.97 -fold $(\mathrm{P}<0.05)$ in saline-treated/ OVA-sensitized mice compared with the saline-treated/ saline-challenged control. LFK reduced the percentage of IL-17-expressing $\mathrm{CD}^{+}$cells to $44.8 \%(\mathrm{P}<0.05)$ compared with saline-treated/OVA-challenged mice (Fig. 5A and B). No significant change was detected in IL-6 expression in these mice. The expression of TGF- $\beta$ showed a tendency to increase in LFK-treated mice, but this was not significant.

\section{Discussion}

In the present study, we clearly showed that oral administration of LFK attenuated allergic airway inflammation along with significantly suppressing Th17 cell development in mice. That may help us to understand the anti-inflammatory effects of probiotics in the prevention of allergic airway inflammation. Studies using other specific strains of probiotic organisms such as Lactobacillus reuteri reported the importance of live but not heat-killed bacteria in maintaining Th2 functional tolerance (9). The reasons for choosing the lysed heat-killed probiotics for this study were the following: first, in the form of lysed heat-killed Enterococcus faecalis FK-23, the effects of LFK had been analyzed in several immunological disorders, such as active cutaneous anaphylaxis and allergeninduced peritoneal eosinophil accumulation. It is suggested that heat-killed probiotics also have potential therapeutic effects as live bacterias. Second, the specific strains of probiotics have anti-inflammatory activities but the relationships between the probiotics and IL-17 suppression have not been discussed. Third, use of lysed heat-killed probiotics rather than live bacteria assisted in maintaining consistency between experiments in mice. Here we show unequivocally that oral administration of LFK to mice attenuated lung inflammation and airway hyperresponsiveness. These findings are in line with the study of Hunt et al (16), who demonstrated that the intragastric administration of heat-killed Mycobacterium vaccae significantly reduced pulmonary inflammation after antigen challenge in OVA-sensitized mice.

We next asked why the pathological features of airway inflammation are inhibited by LFK. Despite clear evidence for strong immunomodulatory properties of LFK, the mechanisms underlying these effects are poorly understood. Here we demonstrated one of the most important effects of probiotics on allergic airway inflammation in mice. That is that oral administration of LFK could suppress Th17 cell development in the intestinal lamina propria, spleen and lung of the asthmatic mice. The importance of IL-17-producing T (Th17) cells rather than Th1 cells or Th2 cells for the development of 
A
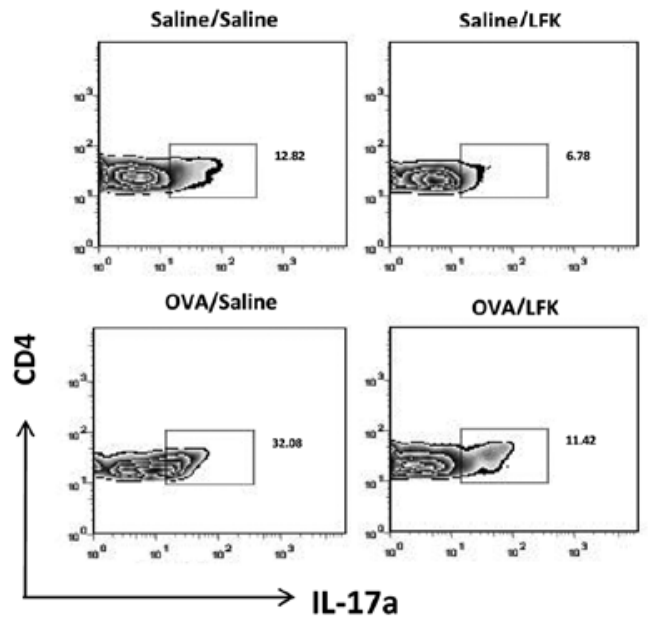

C

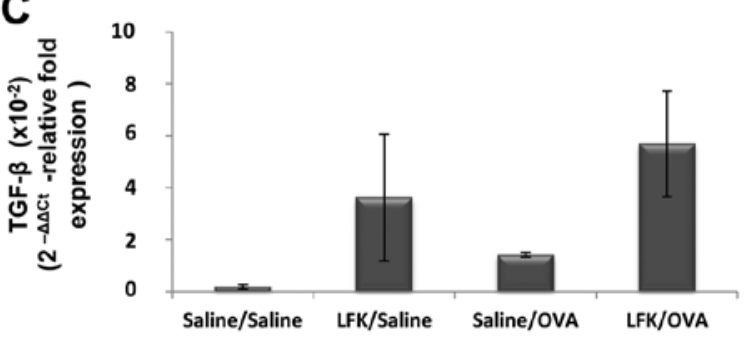

B

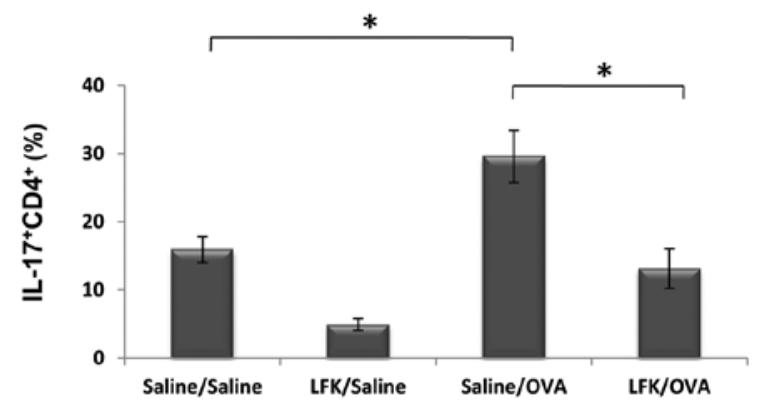

D

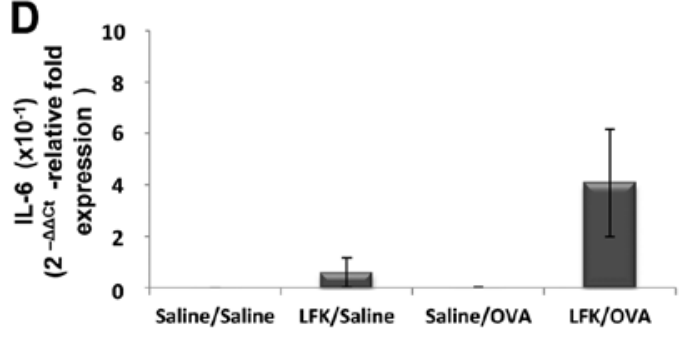

Figure 5. Oral administration of LFK attenuates the development of Th17 cells in the intestine. Lamina propria lymphocytes were obtained as described in Materials and methods for further intracellular cytokine staining. (A) Representative plots and (B) combined data of CD4 and IL-17 expression in lamina propria lymphocytes are shown. Data are from one of at least 3 separate experiments with similar results. (C) IL-6 and (D) TGF- $\beta$ mRNA expression in lamina propria lymphocytes was quantified by real-time PCR. ${ }^{\mathrm{P}}<0.05$, Student's t-test compared with each group. ( $\mathrm{n}=3-5 \mathrm{mice} / \mathrm{group}$ ).

allergic diseases has been demonstrated in IL-17-deficent mice (17). The clinical observations also showed that the concentration of IL-17 was significantly increased in BALF, sputum and blood from patients with asthma $(18,19)$. Exploration of the mechanisms by which Th17 cells differentiate from naïve T cells have shown that IL-6, in synergy with TGF- $\beta$ have a critical role in inducing the differentiation of Th17 cells.

Our data have demonstrated that oral administration of LFK significantly decreased mRNA expression of TGF- $\beta$ as well as IL-6 in lungs (Fig. 3C and D), which may explain the inhibitory effects of oral LFK treatment on Th17 cell development in the local site. In spleens, LFK treatment decreased mRNA expression of IL-6 (Fig. 4D) while suppressing Th17 cell development (Fig. 4A and B). Indeed, IL-6 has key functions in programming naïve $\mathrm{CD}^{+} \mathrm{T}$ cells to become Th17 cells. IL- 6 induced expression of IL-21 that amplified an autocrine loop to induce more IL-21 and IL-23 receptor in naïve and $\mathrm{CD}^{+}$cells. Furthermore, IL- 6 through the STAT3-ROR $\gamma$ t pathway in concert with TGF- $\beta$ are involved in differentiation of Th17 cells (20). Ghoreschi et al (21) showed that Th17 differentiation can occur in the absence of TGF- $\beta$ signaling in mice. Neither IL- 6 nor IL-23 alone efficiently generated pathogenic Th17 cells. On the other hand, IL-6-deficient mice have been shown to have a deficit in Th17 development (22).

In contrast, although the TGF- $\beta$ and IL- 6 mRNA expression levels in intestinal lamina propria were not significantly different between the asthmatic mice and LFK-treated asthmatic mice, both TGF- $\beta$ and IL- 6 showed a tendency to increase in LFK-treated models of asthma. IL-6 is one of the main cytokines produced by intestinal lamina propria cells after infection. For example, overproduction of IL-6 has been found in many types of colitis. Further analyses are needed to clarify whether the expression of IL-6 in intestinal lamina propria cells could be suppressed by LFK. TGF- $\beta$, has a dual function in directing the differentiation of Treg cells and proinflammatory Th17 cells. Whether increased production of TGF- $\beta$ by intestinal lamina propria cells contributed to a shift in the Treg/Th17 balance toward Treg resulting in suppression of Th17 cell development (Fig. 5A and B) needs to be further clarified. It has been reported that Foxp 3 can directly bind to ROR $\gamma$ t to then inhibit ROR $\gamma$ t-dependent transcriptional activation of its key target genes such as IL-17 (23).

Examination of cytokines in the present study was performed in vivo. To mimic the in vivo interaction between probiotics and target cells using an in vitro experiment would be beneficial to investigate the precise mechanism. In fact, in vitro experiments have been extensively performed. Tanabe et al (24) and Jan et al (25) analyzed cytokine production after splenocytes were cultured with Bifidobacterium infantis and Lactobacillus gasseri and demonstrated that these selected probiotics are able to suppress IL-17 production $(24,25)$. Foligne and colleagues demonstrated that mouse bone marrow-derived dendritic cells (DCs) stimulated in vitro with selected Lactobacillus strains, could attenuate colitis via a Tregs-dependent mechanism (26). In vivo studies using DCs have shown that the functional changes in DCs following interaction with probiotics are critical for immune regulation. These selected probiotics can stimulate DC regulatory functions by targeting a specific pattern-recognition receptor (PRR) family, such as Toll-like receptors (TLRs), through DCs expression of various cytokines, such as IL-10, TGF- $\beta$ and 
indoleamine 2,3-dioxygease (IDO), which drive the generation of CD4 $4^{+} 5^{+} \mathrm{Foxp}^{+}$Tregs (27-29). As described above, Foxp3 can inhibit Th17 cells differentiation by antagonizing ROR $\gamma \mathrm{t}$, while, these probiotic-induced Tregs can also inhibit the differentiation of Th1 and Th2 cells (30), which may explain how some probiotic strains could suppress the $\mathrm{Th} 2$ response in asthma model (31).

Although we showed evidence for the attenuation of Th17 cells and related cytokines produced by lung cells and splenocytes following oral administration of LFK, this does not prove the precise mechanism and the LFK component(s) which responded with target cells. Further studies are required to elucidate the nature of the probiotic-host cell interactions, how these interactions induce immunomodulation and to identify the specific component(s) of probiotic and host responsible for these interactions. In addition, the mechanism by which the immunomodulatory effects of oral probiotics treatment influence sites distant to the intestine, such as respiratory tract need to be examined. To address this issue, a gut-lung axis of probiotic action was proposed by Forsythe (32). A literature review shows that the anti-allergic effects of probiotics are strain-dependent and mediated by different effects (33). For example, in contrast to the suppression of IL-17/Th17 by selected probiotics it has been reported that a specific component of the macrobiota, Candidatus arthromitus, a subset of the Firmicute-Clostridiae group commonly termed segmented filamentous bacteria (SFB), promotes Th17 cell induction in the intestine (15).

In conclusion, our results have shown that oral administration of LFK resulted in significant attention of allergic airway response in OVA-sensitized mice. Our data also indicated that oral administration of LFK could suppress the in vivo development of Th17, which may be caused by LFK-mediated restoration of the Treg/Th17 balance though the TGF- $\beta$ and IL-6 cytokine-dependent signaling pathways. Increased knowledge of the regulatory activities of probiotics will stimulate the development of alternative approaches for the treatment of immune disorders via the modulation of T cell-balance.

\section{References}

1. Iwakura Y, Nakae S, Saijo S and Ishigame H: The roles of IL-17A in inflammatory immune responses and host defense against pathogens. Immunol Rev 226: 57-79, 2008.

2. Hurst SD, Muchamuel T, Gorman DM, et al: New IL-17 family members promote Th1 or Th2 responses in the lung: in vivo function of the novel cytokine IL-25. J Immunol 169: 443-453, 2002.

3. Oda N, Canelos PB, Essayan DM, Plunkett BA, Myers AC and Huang SK: Interleukin-17F induces pulmonary neutrophilia and amplifies antigen-induced allergic response. Am J Respir Crit Care Med 171: 12-18, 2005.

4. Park H, Li Z, Yang XO, et al: A distinct lineage of CD4 T cells regulates tissue inflammation by producing interleukin 17 . Nat Immunol 6: 1133-1141, 2005.

5. Yang XO, Chang SH, Park H, et al: Regulation of inflammatory responses by IL-17F. J Exp Med 205: 1063-1075, 2008.

6. Oboki K, Ohno T, Saito H and Nakae S: Th17 and allergy. Allergol Int 57: 121-134, 2008.

7. Blumer N, Sel S, Virna S, et al: Perinatal maternal application of Lactobacillus rhamnosus GG suppresses allergic airway inflammation in mouse offspring. Clin Exp Allergy 37: 348-357, 2007.

8. Feleszko W, Jaworska J, Rha RD, et al: Probiotic-induced suppression of allergic sensitization and airway inflammation is associated with an increase of $\mathrm{T}$ regulatory-dependent mechanisms in a murine model of asthma. Clin Exp Allergy 37: 498-505, 2007.
9. Forsythe P, Inman MD and Bienenstock J: Oral treatment with live Lactobacillus reuteri inhibits the allergic airway response in mice. Am J Respir Crit Care Med 175: 561-569, 2007.

10. Karimi K, Inman MD, Bienenstock $J$ and Forsythe P: Lactobacillus reuteri-induced regulatory $\mathrm{T}$ cells protect against an allergic airway response in mice. Am J Respir Crit Care Med 179: 186-193, 2009.

11. Shimada T, Cheng L, Ide M, Fukuda S, Enomoto T and Shirakawa T: Effect of lysed Enterococcus faecalis FK-23 (LFK) on allergen-induced peritoneal accumulation of eosinophils in mice. Clin Exp Allergy 33: 684-687, 2003.

12. Shimada T, Cheng L, Yamasaki A, et al: Effects of lysed Enterococcus faecalis FK-23 on allergen-induced serum antibody responses and active cutaneous anaphylaxis in mice. Clin Exp Allergy 34: 1784-1788, 2004.

13. Cato MH, Yau IW and Rickert RC: Magnetic-based purification of untouched mouse germinal center B cells for ex vivo manipulation and biochemical analysis. Nat Protoc 6: 953-960, 2011.

14. Sauer KA, Scholtes P, Karwot R and Finotto S: Isolation of CD4 ${ }^{+}$ cells from murine lungs: a method to analyze ongoing immune responses in the lung. Nat Protoc 1: 2870-2875, 2006.

15. Atarashi K, Tanoue $\mathrm{T}$ and Honda K: Induction of lamina propria Th17 cells by intestinal commensal bacteria. Vaccine 28: 8036-8038, 2010.

16. Hunt JR, Martinelli R, Adams VC, Rook GA and Brunet LR: Intragastric administration of Mycobacterium vaccae inhibits severe pulmonary allergic inflammation in a mouse model. Clin Exp Allergy 35: 685-690, 2005.

17. Nakae S, Komiyama Y, Nambu A, et al: Antigen-specific T cell sensitization is impaired in IL-17-deficient mice, causing suppression of allergic cellular and humoral responses. Immunity 17: 375-387, 2002.

18. Molet S, Hamid Q, Davoine F, et al: IL-17 is increased in asthmatic airways and induces human bronchial fibroblasts to produce cytokines. J Allergy Clin Immunol 108: 430-438, 2001.

19. Barczyk A, Pierzchala W and Sozanska E: Interleukin-17 in sputum correlates with airway hyperresponsiveness to methacholine. Respir Med 97: 726-733, 2003.

20. Zhou L, Ivanov, II, Spolski R, et al: IL-6 programs T(H)-17 cell differentiation by promoting sequential engagement of the IL-21 and IL-23 pathways. Nat Immunol 8: 967-974, 2007.

21. Ghoreschi K, Laurence A, Yang XP, et al: Generation of pathogenic $\mathrm{T}(\mathrm{H}) 17$ cells in the absence of TGF-beta signalling. Nature 467: 967-971, 2010.

22. Bettelli E, Carrier Y, Gao W, et al: Reciprocal developmental pathways for the generation of pathogenic effector TH17 and regulatory T cells. Nature 441: 235-238, 2006.

23. Zhou L, Lopes JE, Chong MM, et al: TGF-beta-induced Foxp3 inhibits $\mathrm{T}(\mathrm{H}) 17$ cell differentiation by antagonizing RORgammat function. Nature 453: 236-240, 2008.

24. Tanabe S, Kinuta Y and Saito Y: Bifidobacterium infantis suppresses proinflammatory interleukin-17 production in murine splenocytes and dextran sodium sulfate-induced intestinal inflammation. Int J Mol Med 22: 181-185, 2008.

25. Jan RL, Yeh KC, Hsieh MH, et al: Lactobacillus gasseri suppresses Th17 pro-inflammatory response and attenuates allergen-induced airway inflammation in a mouse model of allergic asthma. Br J Nutr: Oct 14, 2011 (Epub ahead of print).

26. Foligne B, Zoumpopoulou G, Dewulf J, et al: A key role of dendritic cells in probiotic functionality. PLoS One 2: e313, 2007.

27. Kwon HK, Lee CG, So JS, et al: Generation of regulatory dendritic cells and $\mathrm{CD}^{+}{ }^{+} \mathrm{Foxp}^{+} \mathrm{T}$ cells by probiotics administration suppresses immune disorders. Proc Natl Acad Sci USA 107: 2159-2164, 2010

28. Puccetti P and Grohmann U: IDO and regulatory T cells: a role for reverse signalling and non-canonical NF-kappaB activation. Nat Rev Immunol 7: 817-823, 2007.

29. Hart AL, Lammers K, Brigidi P, et al: Modulation of human dendritic cell phenotype and function by probiotic bacteria. Gut 53: 1602-1609, 2004.

30. Belkaid Y: The role of CD4(+)CD25(+) regulatory $\mathrm{T}$ cells in Leishmania infection. Expert Opin Biol Ther 3: 875-885, 2003.

31. Schiavi E, Barletta B, Butteroni C, Corinti S, Boirivant $M$ and Di Felice G: Oral therapeutic administration of a probiotic mixture suppresses established Th2 responses and systemic anaphylaxis in a murine model of food allergy. Allergy 66: 499-508, 2011.

32. Forsythe P: Probiotics and lung diseases. Chest 139: 901-908, 2011 .

33. Michail S: The role of probiotics in allergic diseases. Allergy Asthma Clin Immunol 5: 5, 2009. 